\title{
High Efficiency Liquid-Desiccant Regenerator for Air Conditioning and Industrial Drying
}

Department of Energy Contract No. DE-FG36-03G013170

Final Report

December 19, 2005

\begin{abstract}
Andrew Lowenstein
AlL Research, Inc.

P.O. Box 3662

Princeton, NJ 08543
\end{abstract}

$609-452-2950 \times 40$ 


\subsection{Executive Summary}

Over 2 quads of fossil fuels are used each year for moisture removal. This includes industrial and agricultural processes where feedstocks and final products must be dried, as well as comfort conditioning of indoor spaces where the control of humidity is essential to maintaining healthy, productive and comfortable working conditions. Desiccants - materials that have a high affinity for water vapor — can greatly reduce energy use for both drying and dehumidification.

An opportunity exists to greatly improve the competitiveness of advanced liquid-desiccant systems by increasing the efficiency of their regenerators. It is common practice within the chemical process industry to use multiple stage boilers to improve the efficiency of thermal separation processes. The energy needed to regenerate a liquid desiccant, which is a thermal separation process, can also be reduced by using a multiple stage boiler.

In this project, a two-stage regenerator was developed in which the first stage is a boiler and the second stage is a scavenging-air regenerator. The only energy input to this regenerator is the natural gas that fires the boiler. The steam produced in the boiler provides the thermal energy to run the second-stage scavenging-air regenerator. This two-stage regenerator is referred to as a $1 \frac{1}{2}$-effect regenerator.

A model of the high-temperature stage of a 11/2-effect regenerator for liquid desiccants was designed, built and successfully tested. At nominal operating conditions (i.e., $2.35 \mathrm{gpm}$ of $36 \%$ lithium chloride solution, $307,000 \mathrm{Btu} / \mathrm{h}$ firing rate), the boiler removed $153 \mathrm{lb} / \mathrm{h}$ of water from the desiccant at a gasbased efficiency of $52.9 \%$ (which corresponds to a COP of 0.95 when a scavenging-air regenerator is added). The steam leaving the boiler, when condensed, had a solids concentration of less than $10 \mathrm{ppm}$. This low level of solids in the condensate places an upper bound of about $6 \mathrm{lb}$ per year for desiccant loss from the regenerator. This low loss will not create maintenance problems nor will it significantly increase operating expenses.

An energy balance on the boiler showed that heat loss through the insulated jacket was $10 \%$. This value is much higher than the $2 \%$ to $5 \%$ that is typical of most boilers and indicates a need to better insulate the unit. With insulation that brings jacket losses down to 5\%, a $1 \frac{1}{2}$-effect regenerator that uses this boiler as its high-temperature stage will have a gas-based COP of 1.05 .

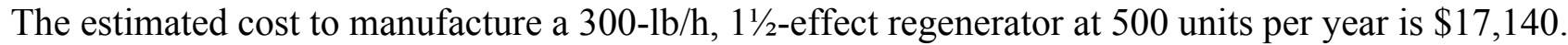
Unfortunately, the very high cost for natural gas that now prevails in the U.S. makes it very difficult for a gas-fired LDAC to compete against an electric vapor-compression air conditioner in HVAC applications. However, there are important industrial markets that need very dry air where the high price of natural gas will encourage the sale of a LDAC with the $1 \frac{1}{2}$-effect regenerator since in these markets it competes against less efficient gas-fired desiccant technologies. A manufacturer of industrial dehumidi-

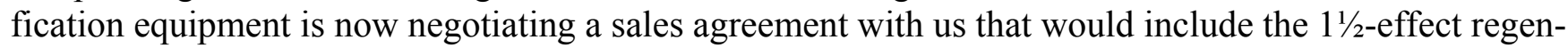
erator.

\subsection{Introduction}

Over 2 quads of fossil fuels are used each year for moisture removal. This includes industrial and agricultural processes where feedstocks and final products must be dried, as well as comfort conditioning of indoor spaces where the control of humidity is essential to maintaining healthy, productive and comfortable working conditions. Desiccants - materials that have a high affinity for water vapor — can greatly reduce energy use for both drying and dehumidification.

The contribution that desiccants have made to industrial drying and space conditioning has been limited by their high first cost, large size, and, for liquid-desiccant systems, high maintenance requirements. However, during the past six years with funding from DOE, AIL Research has developed a new genera- 
tion of liquid-desiccant technology that dramatically improves the cost, size and performance characteristics of these systems. AIL Research has started to commercialize this technology with the set-up of an automated pilot manufacturing line and the field operation of a 6,000-cfm prototype in the fall of 2005 .

An opportunity exists to greatly improve the competitiveness of advanced liquid-desiccant systems by increasing the efficiency of their regenerators. In work sponsored by NREL, AIL Research both modeled the performance of a two-stage regenerator and demonstrated its technical feasibility in a small bench-top test rig. This regenerator-referred to as a $1 \frac{1}{2}$-effect regenerator-has the potential to almost double the efficiency of liquid-desiccant systems.

The objective of the proposed work is to develop and demonstrate the operation of the high temperature stage of a $1 \frac{1}{2}$-effect regenerator. The technical issues are: (1) materials that can resist corrosion by the desiccant while thermally cycling between ambient and $320^{\circ} \mathrm{F}$ must be proven for long-term operation, and (2) stable operation must be proven over a range of operating conditions.

\subsection{The Operation of a Liquid-Desiccant Air Conditioner}

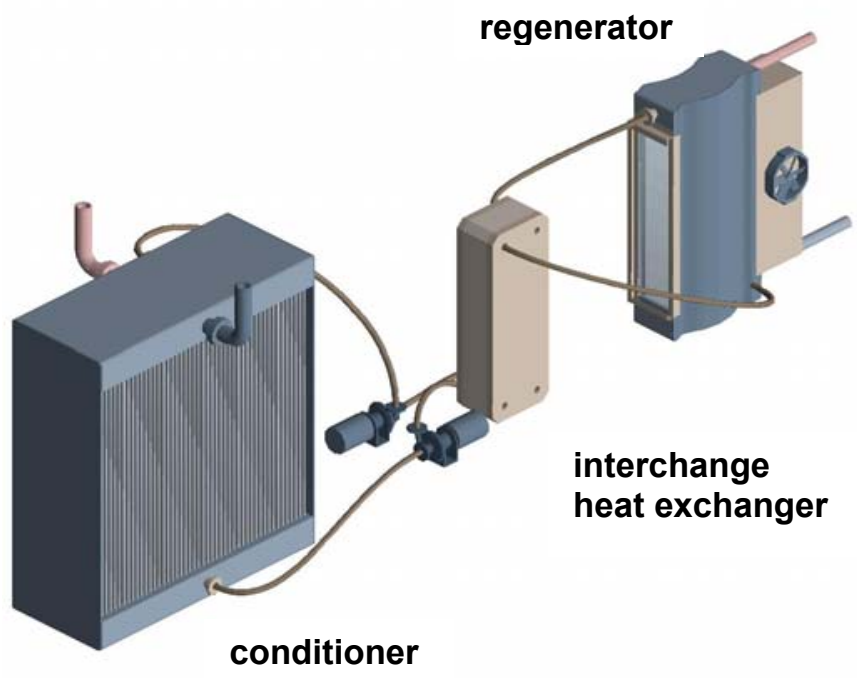

Figure 1 - A Generic Liquid-Desiccant Air Conditioner
As shown in Figure 1, a liquid-desiccant air conditioner (LDAC) has three major components: (1) the conditioner, which dries and cools the process air, (2) the regenerator, which heats the weak desiccant to drive off the water that was absorbed in the conditioner, and (3) the interchange heat exchanger, which uses the hot, concentrated desiccant that leaves the regenerator to preheat the cool, weak desiccant that leaves the conditioner. The conditioner in this figure is a water-to-air heat exchanger that is constructed from plastic plates. Cooling water flows within the plates and films of liquid desiccant flow down the outer surfaces of the plates. Wicks on the plate surfaces uniformly distribute the desiccant. As humid air flows in the gaps between the plates, the

desiccant films absorb the water vapor. The heat released by this absorption is transferred to the cooling water that flows within the plates. The process air leaves the conditioner both drier and at a lower enthalpy (i.e., net cooling).

The regenerator that is shown in Figure 1 operates as the inverse of the conditioner. The regenerator is again a water-to-air heat exchanger. However, now hot water flows within the plates. The hot water heats the desiccant films that flow down the outer surfaces of the plates. As the desiccant's temperature increases, water is desorbed and carried out of the regenerator by a scavenging air stream that flows between the plates.

The scavenging-air regenerator just described requires about 1,650 Btus to remove one pound of water from the desiccant. This corresponds to a regeneration COP of 0.64. A high-efficiency industrial dehumidifier, such as the one manufactured by Nyle Corporation, requires $167 \mathrm{Wh}$ per pound of water. If one assumes that the generation/transmission efficiency for electricity produced at a central power plant is $30 \%$, then 1,900 Btus of primary energy is used for each pound of water removed by the electric dehumidifier. 
The preceding calculation shows a modest $13 \%$ reduction in primary energy when a liquid-desiccant dehumidifier replaces an electric unit. However, the objective of this project is to develop a proof-ofconcept model of a much more efficient regenerator that uses only about one-half the energy of the scavenging-air regenerator. This will provide much more compelling energy savings compared to electric dehumidifiers.

\subsection{The Theoretical Performance of the $1 \frac{1}{2}$-Effect Regenerator}

It is common practice within the chemical process industry to use multiple stage boilers to improve the efficiency of thermal separation processes. The energy needed to regenerate a liquid desiccant, which is a thermal separation process, can also be reduced by using a multiple stage boiler.

In this project, a two-stage regenerator is developed in which the first stage is a boiler and the second stage is a scavenging-air regenerator. Since boiling occurs in only the first stage, this regenerator is referred to as a $1 \frac{1}{2}$-effect regenerator.

As shown in Figure 2, the first stage of the 1 1/2-effect regenerator is an atmospheric boiler. The steam from the first stage has a saturation temperature of $212^{\circ} \mathrm{F}$. This steam provides the thermal energy to run a scavenging-air regenerator.

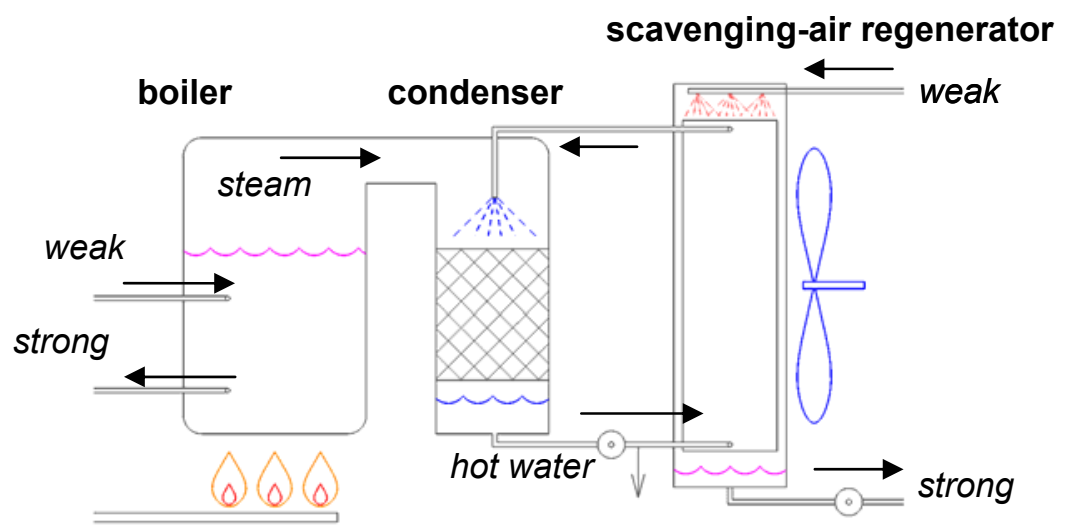

"weak" and "strong" refer to the concentrated and dilute streams of desiccant

Figure 2 - A 11/2-Effect Liquid-Desiccant Regenerator

\subsection{The Development of the 11/2-Effect Regenerator}

The work in this project complements AILR's R\&D activities that are sponsored by the National Renewable Energy Laboratory (NREL) and DOE's SBIR program. The primary objective of these parallel activities is to commercialize a liquid-desiccant air conditioner that runs on relatively low-grade heat. For the SBIR project, the heat source is $160 \mathrm{~F}$ to $200 \mathrm{~F}$ hot water provided by solar collectors, and for the NREL project, it is heat recovered from the cooling loop of an engine-driven electrical generator.

The four main components of the 11/2-effect regenerator are the high-temperature boiler, the lowtemperature scavenging-air regenerator and the two interchange heat exchangers. Both the scavengingair regenerator and the interchange heat exchangers are components required in the NREL and SBIR work, as well as in this project. The development of these lower temperature components was a common effort shared by the three projects. The high-temperature boiler is required only in the $1 \frac{1}{2}$-effect regenerator, and its development was the main objective of this project. 


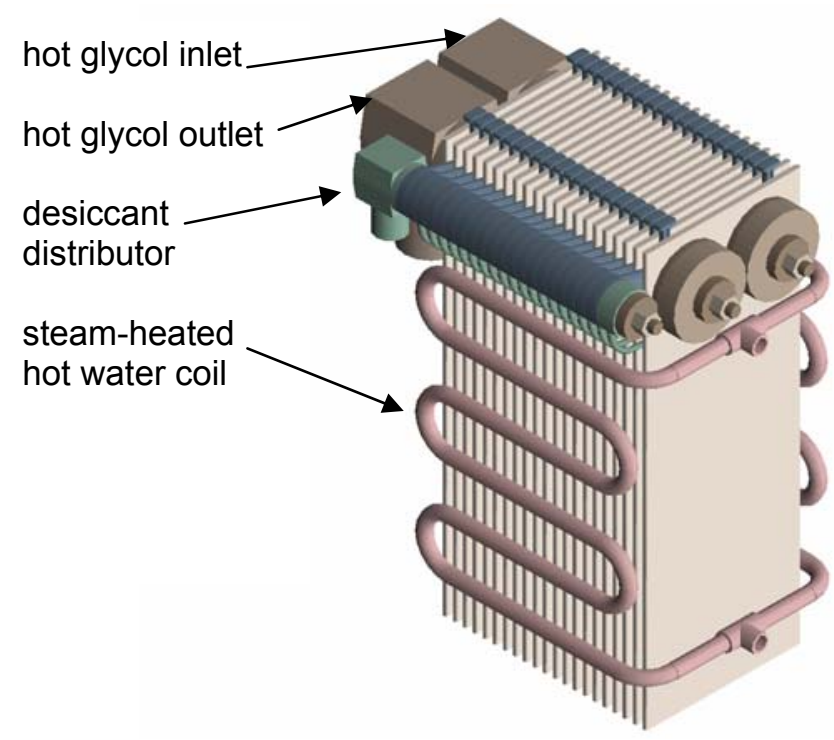

Figure 3 - 11/2-Effect Regenerator

\section{The High-Temperature Boiler}

The proposal for this project described the falling-film regenerator that is shown in Figure 3 as a possible high

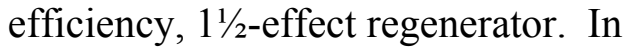
this regenerator, hot glycol recirculates within the coated-aluminum plates of a parallel-plate heat exchanger. Desiccant flows down the outside of the plates. Since the temperature of the glycol is close to the boiling point of the desiccant, atmospheric pressure steam fills the gaps between the plates. This steam condenses on hot water coils located at the front and back of the plate heat exchanger. The hot water in these coils provides thermal energy for a second-stage scavenging-air regenerator.

Early in the project, two critical problems were uncovered in the proposed approach. An aluminumplate regenerator failed after several hundred hours of operation because of several pin-hole imperfections in the coatings. This failure showed the weakness of any concept that relies on flaw-free coatings to protect high temperature metallic surfaces from corrosion by the desiccant.

A second problem was the availability of a fluid heater that could provide glycol to the regenerator at a temperature of approximately $300 \mathrm{~F}$. This temperature is beyond the operating range of common water heaters. While steam boilers do operate at this temperature, they are large, expensive and relatively complicated to control and maintain. It was judged unlikely that a $1 \frac{1}{2}$-effect regenerator that was based on the concept shown in Figure 3 would lead to a competitive product.

A direct-fired desiccant boiler was proposed in place of the original falling-film design. Bench-top experiments were set to study the feasibility of two different boiler configurations. The two configurations are referred to as (1) vertical fired-tube boiler, and (2) spiral liquid-tube boiler.

The vertical fired-tube boiler is made of an array of vertical tubes that extend up through a pool of desiccant. Hot combustion products from a gas flame flow up through the inside of the tubes. A turbulator within the tubes enhance heat transfer from the combustion products to the tube wall. Boiling occurs within the desiccant pool. Steam exits from the top of the boiler. Weak desiccant flows into the pool through a submerged inlet tube and strong desiccant flows out through a second submerged tube.

The spiral liquid-tube boiler is made from a single coiled tube that is finned on the outside. Desiccant is pumped through the inside of the tube and hot combustion products are drawn over the outside of the tube. This boiler is a "once through" design in which weak desiccant is pumped into the bottom of the tube and a two-phase (vapor and liquid) mixture exits at the top of the tube. A steam/droplet separator receives the two-phase mixture and delivers a droplet-free steam flow to the low-temperature stage of the regenerator.

The operation of a vertical fired-tube boiler was explored in the single-tube test rig shown in Figures 4. The high corrosivity and high chloride concentration of the desiccant (a solution of lithium chloride) eliminates most alloys from this application. After screening several high-nickel alloys, hastelloy was selected for the fired tube. The tube outer diameter was 1.5". The tube was welded to a bottom base 
plate that was 0.050 " hastelloy. A 2.875 " diameter glass tube was centered over the fired tube and sealed to the base plate with a silicone adhesive.

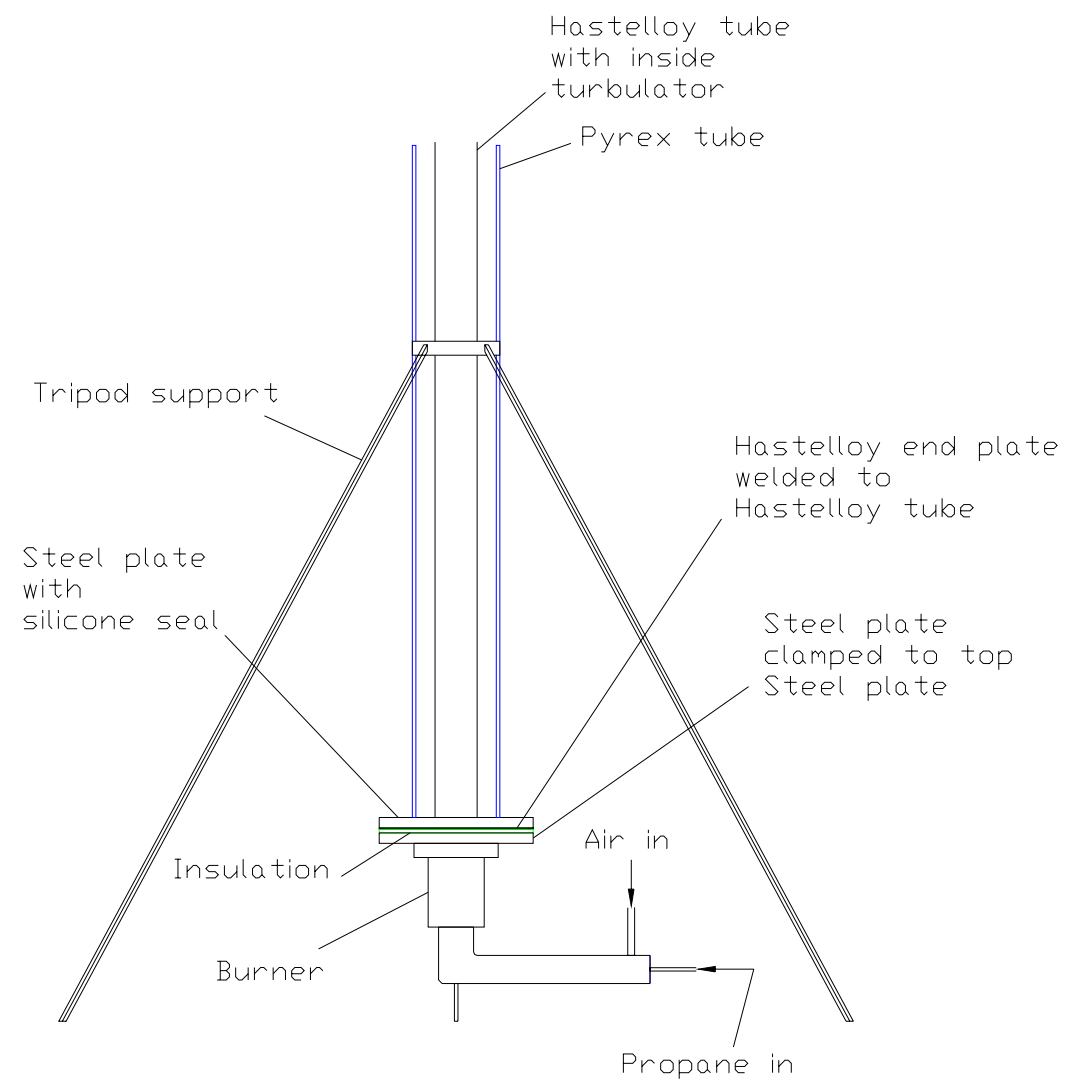

Figure 4 - Fired-Tube Boiler Test Rig

A simple pre-mix combustor was built for firing the test rig. Initial tests with water proved the basic operation of the test rig.

Our primary objectives in building and testing the fired-tube boiler were to:

- Understand the behavior of boiling lithium chloride, particularly with the depth of the bubble layer that forms on top of the pool

- Assess the difficulty in separating a droplet-free stream of steam from the boiler

- Estimate the heat transfer coefficient between the combustion gas and the tube wall so that a full scale boiler could be sized.

When fired at the design rate of $8,150 \mathrm{Btu} / \mathrm{h}$, extremely vigorous boiling occurred within the test rig. As directly viewed through the glass outer wall, almost the entire liquid pool was filled with bubbles. To prevent overflowing of liquid out the top of the glass tube, the initial charge of desiccant in the boiler was limited to a 10" depth (with the total height of the glass tube being 24").

Steam and liquid naturally separated within the boiler as the bubbles burst at the top of the bubble layer. Although we did not attempt to measure the droplet size, we expect that droplets on the order of 10 to 20 
micron diameter are forming as the bubbles burst. These droplets are relatively large and could be easily removed from the steam by either in inertial or centrifugal means of separation.

Rather than calculate a heat transfer coefficient between the combustion gas and the tube wall, we measured the overall efficiency of the combustion/heat-transfer process. This was done by measuring the gas and air flow to the test rig and then measuring the amount of water desorbed from the desiccant over specified period of time. With a simple twisted-strip turbulator within the fired tube (to promote heat transfer) we estimate that the 1.5 " diameter fired tube transferred about $40 \%$ to $50 \%$ of the released

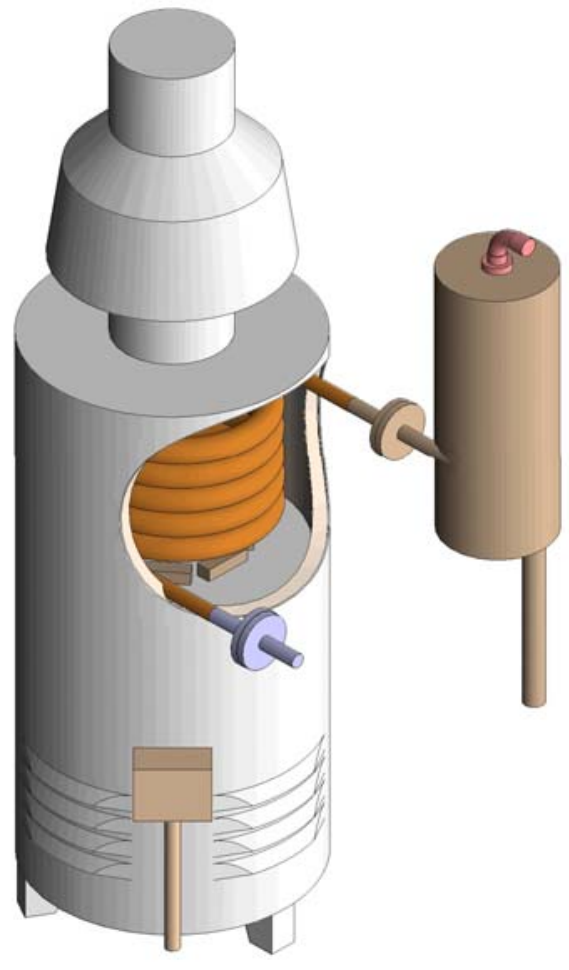

Figure 5 - Spiral Liquid-Tube Boiler heat of combustion to the desiccant. This overall heat-transfer efficiency is too low for a practical desiccant boiler. Some combination of increased heat transfer and/or longer tube length would need to be used in the final boiler design.

At the same time that we were performing the single fired-tube boiler tests, we spoke with manufacturers of specialty boilers to determine a ball-park cost for manufacturing this type of boiler. Although we did not get a quote for manufacturing, we were warned that the procedure for welding about thirty 1.5 "'diameter hastelloy tubes to a flat tube sheet would be expensive. Although hastelloy can be welded fairly easily, serious warping is introduced. Welding without introducing warping is more of an art than a science, and can be expensive to develop.

While the vertical fired-tube boiler is technically feasible, the preceding cost concerns led us to study a second configuration: the spiral liquid-tube boiler that is shown in Figure 5. This configuration has the advantage that it can be assembled with little or no welding. At the start of this study we got quotes for fabricating the spiral hastelloy coil with external fins that would be used in this concept. At moderate volumes, the selling price to us would be about $\$ 600$. A coil for prototyping would cost $\$ 3,200$. These prices are very reasonable and well within our targets for both a commercially viable system and a prototype. (Costs for corrosion-resistant alloys increased dramatically during the period of performance for this project. Our manufacturing cost analysis for the $1 \frac{1}{2}$-effect regenerator reflect alloy prices in the fall 2005.)

The problem of separating droplets from the steam that leaves the boiler will be much more difficult for the spiral liquid-tube design. In this boiler, approximately $10 \%$ of the mass of desiccant is converted to steam as the desiccant flows through the tube. Since the steam has approximately $1 / 1000^{\text {th }}$ the density of the liquid, the velocity of the two-phase flow that leaves the boiler is about 100 times higher than the entering flow. If weak desiccant enters at 1 foot per second, the two-phase flow will exit at about 100 feet per second. At this velocity, the high liquid-gas shear present will produce very small droplets. These small droplets are much more difficult to separate from the steam than those created in the vertical fired-tube boiler.

Before designing and building a test rig for the spiral liquid-tube boiler that could operate continuously, we set up a relatively simple "batch" test rig. In this test rig, approximately 50 gallons of desiccant were preheated to about $140 \mathrm{~F}$ and stored in a conventional water heater. Rather than work with lithium chloride, which is fairly expensive, we used a $20 \%$ solution of potassium chloride as the desiccant. This solution at $140 \mathrm{~F}$ is denser than the cold water that is delivered from the spigot in our lab. Therefore, by feeding cold water to the top of the storage tank and drawing the hot desiccant from the bottom, we 
could deliver almost 50 gallons of desiccant at flow rate that could be easily varied between 1 gpm and 3 gpm.

The desiccant from the storage tank was delivered to the inlet of a conventional spiral-tube boiler manufactured by Ace Boiler Company. This boiler has a copper tube which, although not designed to operate with a salt solution, has a sufficient lifetime for our tests.

The two-phase mixture from the boiler immediately entered a cyclone separator that was made from clear polycarbonate. The polycarbonate can operate at up to $250 \mathrm{~F}$. It was easily fabricated, and its transparency allowed the operation of the separator to be viewed.

An initial test with a 2" diameter separator was not successful at delivering a "dry" steam flow from the top of the separator. With this small diameter, a very large fraction of desiccant was entrained with the steam leaving the separator.

In our second series of tests, we used a 6" diameter separator. These tests were much more successful. During design operation, it was not possible to visually detect any droplets in the steam leaving the separator. Furthermore, when the $90^{\circ}$ elbow at the top of the separator was heated so that it was free of condensate, no droplets or salt deposit were seen to accumulate on the wall.

During the test of this boiler, we probed the top portion of the separator with a helium-neon laser. The laser beam was clearly visible within the top portion of the separator, which indicates scattering of the light by droplets. We do not know if these droplets are entrained salt solution or condensed steam. In addition, when the laser beam was directed to the 1" outlet at the top of the separator, the path of the beam could not be detected. This would imply that no droplets (either desiccant or condensed water) were leaving the separator (or that the droplets were much smaller than the wavelength of light from the helium-neon laser).

The successful operation of the copper-coil boiler with potassium chloride gave us sufficient confidence to retrofit the boiler with a hastelloy coil. This modification allowed continuous operation without corroding the coil.

The test facility was modified for continuous operation with lithium chloride. The "batch" water heater was replaced with a sump from which desiccant could be pumped through the boiler. The steam leaving the top of the separator flowed into an air-cooled condenser (i.e., a car radiator). Both the condensate from condenser and the hot, concentrated desiccant that drained from the bottom of the separator flowed back to the sump. A water-cooled heat exchanger kept the sump from overheating.

A polysulfone interchange heat exchanger, which is described in more detail in the following section, was added to the test facility to improve the regenerator's efficiency. This heat exchanger preheats the warm, weak desiccant that is pumped to the boiler using the hot, concentrated desiccant that leaves the separator.

The polycarbonate separator, which was developing leaks at its solvent-welded joints after the first series of tests, was replaced with a glass separator of similar geometry.

During continuous operation of the boiler with lithium chloride, samples of condensate were collected. The water in these samples was evaporated. Any solid residue that remained was assumed to be from carryover of desiccant droplets in the steam. In all cases the amount of residue was so small that it was impossible to distinguish the amount of solid residue in samples that were collected when the boiler operated with lithium chloride solution and when it operated with tap water. (The runs with tap water were our "null" experiment. They indicated that we were probably leaching some material from the inside of the condenser.) In all cases, the upper limit on desiccant carryover was about the $10 \mathrm{ppm}$ limit that we have set as acceptable. 
Once the effectiveness of the separator was confirmed, tests focused on the control of the boiler/separator. It was noted that the level of desiccant in the separator could change quickly as the static pressure within the separator and the dynamic pressure of the spinning desiccant changed. This presented control problems since both a too high and a too low liquid level within the separator would lead to either carryover of desiccant out of the separator or a loss of steam. During a typical test, the flow valves that controlled desiccant flow into and out of the separator where continuously adjusted to maintain an acceptable liquid level.

We made two changes to the test rig in an effort to greatly broaden the conditions under which it could operate without adjustments to the flow valves. First, we increased the diameter of the steam lines that connect the separator to the radiator. This change greatly reduced the static pressure in the separator.

In the second change, we added a baffle in the bottom of the separator to suppress the spin in the liquid that is induced by the high-speed flow of desiccant and steam that enter the separator tangentially. (The top of the baffle is several inches below the point where the two-phase steam/desiccant mixture enters the separator and so it does not suppress the rotation of the mixture.) This baffle is the brown plastic plate with two holes in its bottom that is shown in Figure 6.

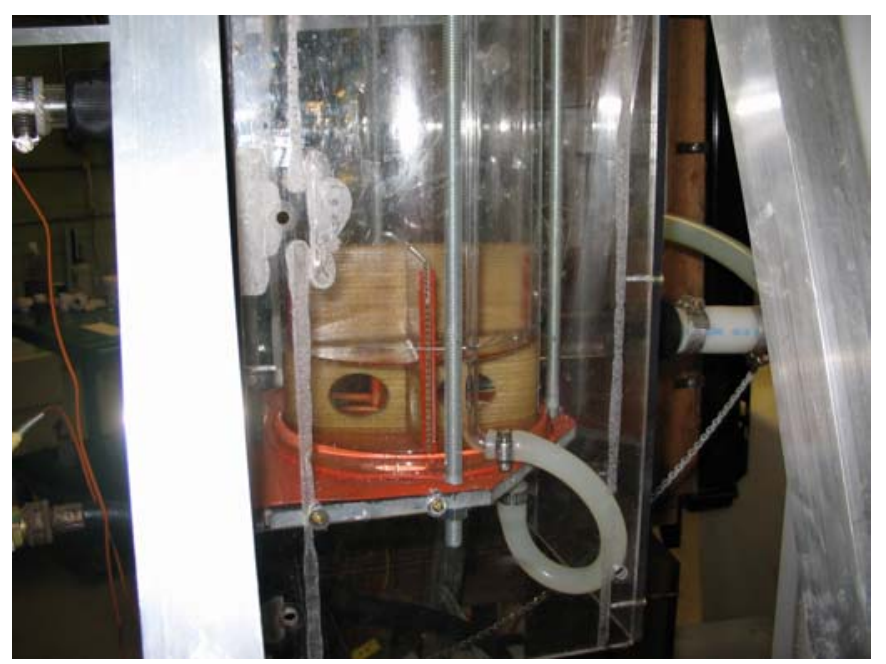

Figure 6 - Baffle Plates at Bottom of Glass Separator

Both of the preceding changes were very effective at making the liquid level within the separator much less sensitive to operating conditions. We were able to operate for periods of over an hour without making changes to the desiccant flow valves at the inlet and outlet to the separator.

With the ability to stably operate for long periods of time, it was possible to measure both the thermal efficiency of the boiler and the particle-removal efficiency of the separator during steady-state operation.

Both high-firing rate and low-firing rate tests were performed on the boiler and separator. The highfiring rate test was at $307,000 \mathrm{Btu} / \mathrm{h}$, which is close to the 300,000 nominal firing rate of the boiler.

The desiccant flow was $2.35 \mathrm{gpm}$ of $35.6 \%$ lithium chloride. At this firing rate, $153 \mathrm{lb} / \mathrm{h}$ of condensate was generated, producing a 4.3 point increase in desiccant concentration. The effectiveness of the interchange heat exchanger was estimated to be $85 \%$. The upper limit on lithium chloride in the condensate was 6 to $10 \mathrm{ppm}$, which is within the design specification. At these operating conditions, the gas-based COP for the boiler was $52.9 \%$. Assuming that the steam-fired scavenging-air stage regenerates desiccant at a thermal COP of 0.8 , the overall gas-based $\mathrm{COP}$ for the regenerator will be 0.95 . (In a preceding section, we stated that the COP for a scavengingair regenerator was 0.64 . This efficiency assumes that an $80 \%$ efficient gas-fired water heater provides thermal energy to the regenerator, which has a COP of 0.8 based on the thermal energy it receives.)

The low-firing rate test was at $170,000 \mathrm{Btu} / \mathrm{h}$, which is about $55 \%$ of the nominal firing rate of the boiler. The desiccant flow was reduced to $1.64 \mathrm{gpm}$, and desiccant inlet concentration was $31.9 \%$ lithium chloride. At this firing rate, $85.2 \mathrm{lb} / \mathrm{h}$ of condensate was generated, producing a 3.1 point increase in desiccant concentration. The effectiveness of the interchange heat exchanger was estimated to be $86 \%$. The upper limit on lithium chloride in the condensate was $5 \mathrm{ppm}$, which is again within the design specification. At these operating conditions, the gas-based COP for the boiler was 53.1\%. Again, as- 
suming that the steam-fired scavenging-air stage regenerates desiccant at a thermal COP of 0.8 , the overall gas-based COP for the regenerator will be 0.96 .

The COP that is measured at the high firing rate is slightly lower than the value of 1.0 that was the original design value (i.e., the original design estimated a COP of 1.25 based on thermal energy delivered to the desiccant and a gas flue efficiency of 0.8 for the boiler). A detailed analysis of the thermal energy flows within the boiler showed that the low COP was due to higher than expected jacket losses. Approximately $10 \%$ of the heat of combustion was lost through the jacket of the boiler. This loss is more than twice the value that the manufacturer of the boiler reports as typical. This higher loss is caused partly by the higher operating temperature of the boiler - a hot-water boiler operates at a maximum temperature of about $180 \mathrm{~F}$, while the desiccant boiler operates closer to $290 \mathrm{~F}$.

The final design for the $1 \frac{1}{2}$-effect regenerator has thicker jacket insulation to reduce jacket losses to less than $5 \%$ of the firing rate. With these lower loses, the COP of the $1 \frac{1}{2}$-effect regenerator will be between 1.00 and 1.05 .

\section{The Scavenging-Air Regenerator}

As noted earlier, both the scavenging-air regenerator and the interchange heat exchanger required by the $1 \frac{1}{2}$-effect regenerator are components required in liquid-desiccant systems that AILR is developing (or has developed) for DOE in work sponsored by NREL and the SBIR program. In this section, we summarize the work that has been done under the three programs.

At the start of this project, the most promising design for the scavenging-air regenerator was one that used an aluminum plate heat exchanger as the contact surface. The aluminum plates were coated to protect them from corrosion. Figure 7 shows a sample of the aluminum extrusion and the coated plate. Unfortunately, duration testing of an aluminum-plate regenerator led to failures of the coating, and eventually, perforation of the plates.

The failure of the aluminum-plate regenerator (and the apparent difficulty in producing a flaw-free coating for the aluminum plates) led to the development of alternate plastic-plate designs for the regenerator. Both the NREL and SBIR projects could meet their objectives with a regenerator that operated at $180 \mathrm{~F}$. For the $1 \frac{1}{2}$-effect regenerator, the high temperature boiler produces steam with a $212 \mathrm{~F}$ saturation tem-

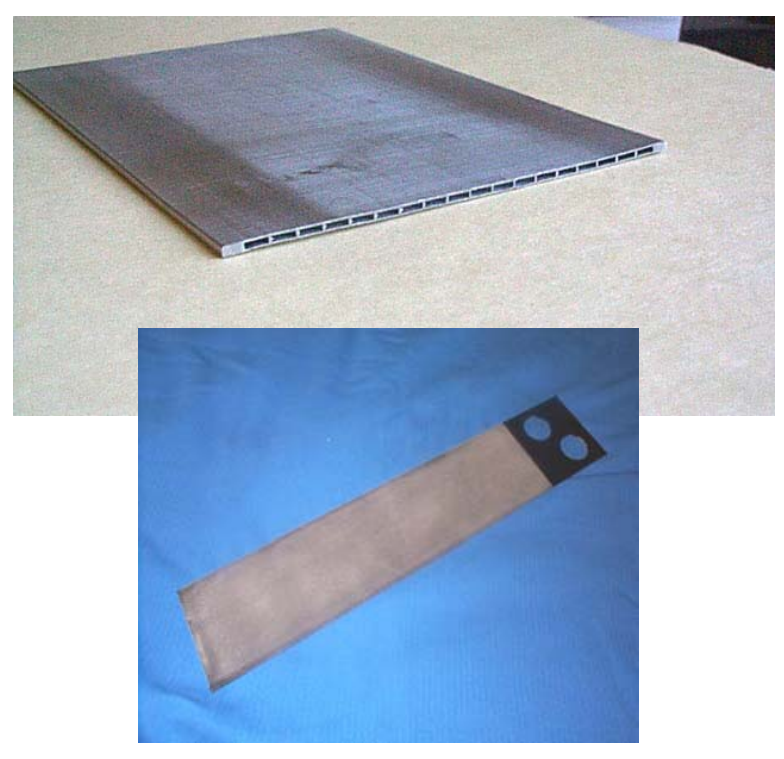

Figure 7 - Regenerator Plate and Extrusion perature. While this thermal energy could be degraded to $180 \mathrm{~F}$, the loss in operating temperature would also degrade the capacity and efficiency of the second stage. Because of these differing requirements, both a $180 \mathrm{~F}$ and a $212 \mathrm{~F}$ scavenging-air regenerator were pursued.

A scavenging-air regenerator is functionally similar to a liquid-desiccant conditioner (i.e., the component that dries and cools the process air). Both these components are plate heat exchangers with desiccant flowing on the outside of the plates, a heat transfer fluid flowing within the plates, and air flowing in the gaps between plates. For the $180 \mathrm{~F}$ regenerator, we first modified a proven design for a conditioner that runs at fluid temperatures up to $120 \mathrm{~F}$. The modification consisted of converting all plastic parts from PVC to CPVC (a resin that is used in hot water pipes that operate at temperatures up to $180 \mathrm{~F}$ ). 
Unfortunately, the conversion to CPVC was not straightforward. Tests for the CPVC regenerator operating on $180^{\circ} \mathrm{F}$ hot water provided by a gas-fired water heater immediately uncovered problems. Within less than one hour, an adhesive joint failed in the regenerator and heat transfer fluid leaked into the desiccant.

Over a period of 14 months, the design of the CPVC regenerator and the procedures for its assembly underwent at least four major modifications. The principal problems that were addressed included: (1) incompatibility of the CPVC resin that was used to make the plates with hot water, (2) adhesion problems between the PMMA adhesive and the CPVC resin that was used to make the manifolds of the regenerator, and (3) stress concentrations induced by differential thermal expansion within the regenerator.

Although the design modifications greatly extended the operating life of the CPVC regenerator, the demonstrated life was not sufficient for a commercial product. All work on the CPVC regenerator stopped after an adhesive joint in a full-scale prototype failed after 600 hour of operation as part of a roof-top liquid-desiccant air conditioner.

Two designs were pursued for the $212 \mathrm{~F}$ scavenging-air regenerator. The first design was made of Noryl, an engineering plastic made by GE that can work at $260^{\circ} \mathrm{F}$. The other was made of Ultem, an engineering plastic made by GE that can work at over $325^{\circ} \mathrm{F}$. The parts of the Noryl regenerator were solvent welded together, and the parts of the Ultem regenerator were both thermally welded and gasketed together.

Both regenerators were installed on a thermal loop that circulated hot fluid within the units. After about two weeks, the Noryl regenerator developed several significant leaks where either welded joints failed or cracks developed in the plates of the structure. The Ultem regenerator developed cracks in the plates and leaks in the thermally welded seals after about four weeks of operation.

The most viable design for the scavenging-air regenerator uses plates extruded from PPSU. PPSU has the highest operating temperature $(350 \mathrm{~F})$ of the polymers that were considered for this application, and it is the most chemically inert. Unfortunately, at approximately $\$ 10$ per pound, it is also the most expensive.

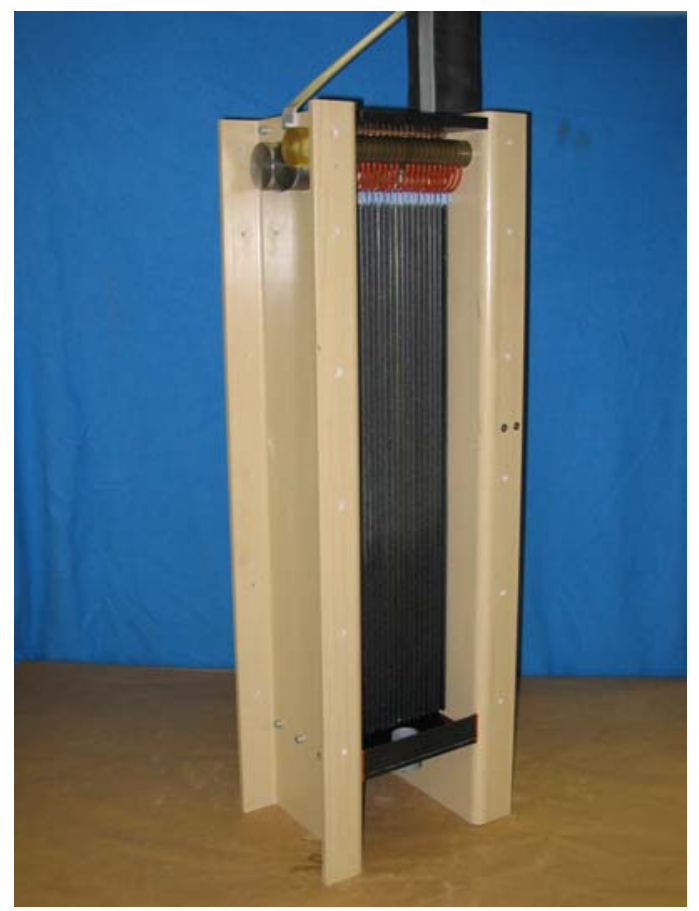

Figure 8 - PPSU Regenerator
A 70-plate prototype of the PPSU regenerator, which is similar to the one shown in Figure 8, successfully completed a 250-hour field test in the fall of 2005. During this test the regenerator operated on $210 \mathrm{~F}$ hot water. An inspection of the regenerator at the conclusion of the test did not uncover any potential failure mechanisms. This design of the PPSU regenerator is used in the following section to estimate the manufacturing costs for a $1 \frac{1}{2}$-effect regenerator.

\section{The Interchange Heat Exchanger}

The first interchange heat exchanger that was tested with the spiral-tube boiler was made from 21 thermoformed polysulphone plates. Prior to operation with the boiler, this heat exchanger was tested with hot water flowing on one side and cold water on the other. At design flow rates, the heat exchanger had an effectiveness of close to $80 \%$ (which was our target effectiveness for this component).

During the highest temperature operation of the boiler (with the most concentrated desiccant), the thermal stresses on the interchange heat exchanger produced cracks in its plates. We 
disassembled the heat exchanger and determined that the cracks were too large to permit continued testing with this unit.

A second interchange heat exchanger was fabricated with plates made from PPSU instead of polysulfone. This heat exchanger operated for approximately 50 hours at temperatures up to $300 \mathrm{~F}$. Its effectiveness was between $80 \%$ and $85 \%$. The heat exchanger successful passed a pressure test following this operation, indicating that the plates had not developed cracks.

This design of the PPSU interchange heat exchanger is used in the following section to estimate the manufacturing costs for a $1 \frac{1}{2}$-effect regenerator.

\subsection{The Cost to Manufacture the $1 \frac{1}{2}$-Effect Regenerator}

Figure 9 shows a packaged 11/2-effect regenerator that has a capacity of $300 \mathrm{lb} / \mathrm{h}$ of water removal. This unit has two spiral-tube boilers each fired at 150,000 Btu per hour. Separate interchange heat exchangers preheat the weak desiccant flows to the boiler and to the scavenging-air regenerator.

The cost to manufacture the $300 \mathrm{lb} / \mathrm{h}$ regenerator was estimated based on the following assumptions:

$\begin{array}{ll}\text { Manufacturing volume: } & 500 \text { units per year } \\ \text { Amortization of tooling: } & 3 \text { years } \\ \text { Labor rate for assembly worker: } & \$ 28.80 \text { per hour } \\ \text { Labor rate for supervisor: } & \$ 43.20 \text { per hour }\end{array}$

where the labor rates include overhead costs (i.e., burdened rates).

At 500 units per year, the costs to manufacture the major components of the $1 \frac{1}{2}$-effect regenerator are:

$\begin{array}{lll}\text { Boiler/separator } & \$ 4,100 \text { per unit } & 2 \text { units required } \\ \text { Interchange HX } & \$ 1,370 \text { per unit } & 2 \text { units required } \\ \text { Scavenging-air regenerator } & \$ 2,200 \text { per unit } & 1 \text { unit required }\end{array}$

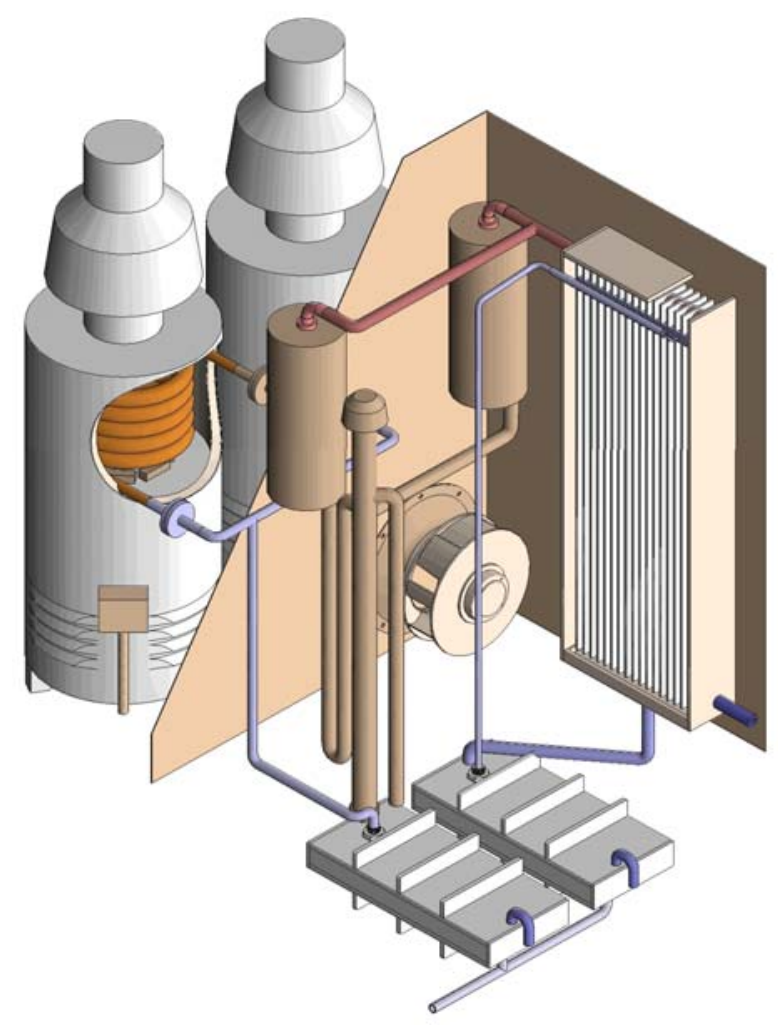

Figure 9 - Packaged 11/2-Effect Regenerator

The total cost for the major components is $\$ 13,140$.

As shown in Figure 9, the major components are assembled onto a single frame. All components other than the two boilers are packaged within an enclosure. A centrifugal blower draws ambient air through a filter and discharges the air into the plenum formed by the enclosure. Air from this plenum flows through the scavenging-air regenerator and is discharged to ambient.

In addition to the major components, the configuration shown in Figure 9 requires a frame, enclosure, blower, controls, louver, and filter. The entire assembly must also be plumbed and wired. These components, and their integration into the regenerator adds approximately $\$ 4,200$ to the manufacturing cost. The total cost to manufacture the regenerator will be $\$ 17,140$. An approximate cost to dealers would be $\$ 20,500$, and to end-users, $\$ 24,700$.

With a capacity of $300 \mathrm{lb} / \mathrm{h}$ of water removal, this regenerator would be used on a 6,000-cfm LDAC that processed outdoor air. With the cooling tower in- 
cluded, the cost of this LDAC will be approximately $\$ 60,000$. This first cost about $25 \%$ higher than that for an electric vapor-compression air conditioner that is designed to process outdoor air.

\subsection{The Competitiveness of the Liquid-Desiccant Air Conditioner}

In HVAC applications, a liquid-desiccant air conditioner (LDAC) will provide much better dehumidification than a conventional electric vapor-compression air conditioner. Early applications for the LDAC will take advantage of this superior latent cooling (i.e., dehumidification).

Recent changes to ASHRAE standards have almost tripled the volume of fresh air that must be used to ventilate a building. In the eastern half of the U.S., where ambient humidity is often very high in the summer, the need to dehumidify the ventilation air can exceed the latent cooling capacity of a conventional vapor-compression air conditioner. The major HVAC manufacturers have recognized this problem, and they all now sell advanced electric air conditioners that provide a greater fraction of their total cooling as latent cooling. However, these high-latent air conditioners have higher first costs and operating costs.

We studied the competition between the LDAC and a high-latent vapor-compression air conditioner in an application where both units cool and dry the ventilation air to a building. For this comparison, the electric alternative functions like the DesChamps Wringer in which an air-to-air heat-pipe heat exchanger transfers heat from the warm air entering the unit's evaporator to the cool air leaving the evaporator. The effect of this transfer is to reheat the air that is delivered to the building, which lowers its relative humidity, while pre-cooling the air entering the evaporator, which increases the amount of latent cooling performed by the air conditioner. Whereas a conventional air conditioner has a latent-cooling fraction of about $30 \%$, the use of the air-to-air heat exchanger will increase this fraction to near $60 \%$.

The operating costs for the LDAC were compared to those for a high-latent conventional air conditioner when both units were processing $12,000 \mathrm{cfm}$ of ventilation air to a retail store in Tampa, FL. The air conditioners operated for the 12-hour period from 9 AM to 9 PM, seven days per week. Also, $10,800 \mathrm{cfm}$ of exhaust air was used to run the cooling tower that is part of the LDAC. Performance was based on TMY2 weather data for Tampa.

The vapor-compression air conditioner will have higher power requirements for the process fan due to the relatively high air-side pressure drops through both sides of the heat-pipe heat exchanger. The LDAC will have higher power requirements to run its pumps and the cooling tower. The additional power requirements for both systems will be on the same order, and they are assumed to cancel each other in the economic comparison.

In this application, the LDAC provides almost all of its cooling as latent: the total cooling is 1,483 million Btu of which $97 \%$ (1,437 million Btu) is latent cooling. The vapor-compression alternative provides 1,619 million Btu total cooling, of which 67\% (1,088 million Btu) is latent cooling.

With the $1 \frac{1}{2}$-effect regenerator, the regeneration COP for the LDAC will be 1.05 . At this efficiency, the gas-fired LDAC will use 1,370 million Btu of natural gas. The vapor-compression air conditioner will use $124,900 \mathrm{kWh}$.

It is not fair to simply compare the preceding gas use for the LDAC with the electric use for the vaporcompression air conditioner. The LDAC is providing 349 million Btu more of latent cooling, but the vapor-compression air conditioner is providing 136 million Btu more of total cooling. In some applications, the additional latent cooling provided by the LDAC will be more valuable than the additional power used by the building's central air conditioner to make up for the LDAC's lower total cooling. At this point, we assume that the additional latent cooling has a value that balances the lower total cooling. 
In July 2005, the average commercial electric and gas rates in Florida were \$0.0796 per kWh and \$11.1 per million Btu. At these rates, the operating costs for the two systems are $\$ 9,942$ for the vaporcompression air conditioner and \$15,207 for the LDAC.

Natural gas prices in the U.S. were at historic highs during the summer and fall of 2005 . For the preceding example, the LDAC and the electric vapor-compression air conditioner would have equal operating costs if gas prices were $\$ 7.26$ per million Btu and electric rates stayed at $\$ 0.0796$ per $\mathrm{kWh}$. This electric-to-gas price ratio, which did apply in much of the country during the relatively low gas prices of the late 1990s and early 2000s, now occurs in the urban centers of the Northeast.

The forecast of the U.S. Energy Information Administration shows natural gas and electric commercial prices decreasing from 2006 to 2010 . The decrease for natural gas is about $20 \%$ to an average U.S. price of $\$ 8.80$ in 2010 , and for electricity, about $10 \%$ to $\$ 0.076$ per $\mathrm{kWh}$. At these projected prices, the electric vapor-compression air conditioner will still have lower operating costs than the LDAC. The LDAC is likely to be a regional product, most successful in the humid Northeast where electric energy rates and demand charges are very high and end-users will be willing to pay a premium for its high latent cooling capacity.

\subsection{Commercialization Activities}

The price increases for natural gas that have occurred since the start of this project have made it very difficult for all gas-fired cooling and dehumidification technologies to compete against electric vaporcompression systems in HVAC applications. However, in industrial applications that must maintain very low humidity, a desiccant system, either solid or liquid, is the only option. In these applications, the $1 \frac{1}{2}$-effect regenerator, with a COP of 1.05 , will have much lower operating costs than either a soliddesiccant or conventional liquid-desiccant system, both of which have gas-fired COPs that are close to 0.5 .

In early 2005, the chief engineer of a manufacturer of liquid-desiccant dehumidification equipment stated that he would be interested in the $1 \frac{1}{2}$-effect regenerator if he could purchase a $300 \mathrm{lb} / \mathrm{hr}$ unit for approximately $\$ 15,000$. This price is below the estimated cost to manufacture the regenerator that was presented in an earlier section. However, this comparison does not reflect the price increases in natural gas that have occurred in the last half of 2005 and the general uncertainty that now exists. We are now negotiating a sales agreement with this manufacturer which will included the $1 \frac{1}{2}$-effect regenerator in addition to the one-stage scavenging-air regenerator and the liquid-desiccant conditioner that we have developed.

Work is also continuing on design changes that will reduce the cost to manufacture the $1 \frac{1}{2}$-effect regen-

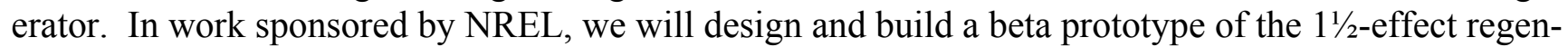
erator. The beta prototype is scheduled to be completed in the spring of 2006.

\subsection{Conclusions}

Although indoor humidity control is now recognized as a critical problem in HVAC applications, it will be difficult for a gas-fired liquid-desiccant air conditioner, even one with a COP greater than 1.0, to compete with the new generation of electric air conditioners that are designed to serve large latent loads. The principal obstacle for the gas-fired LDAC is the high cost of gas that now exists in all parts of the country and the uncertainty in future supplies. At prices for gas and electricity that now exist in most of the country, the high-efficiency LDAC will cost between $30 \%$ and $50 \%$ more to operate than its electric counterpart. The difference in operating costs disappears in some urban markets of the Northeast, but even in these markets sales of the LDAC will be hampered by uncertainties in future availability and 
price of natural gas. The high-efficiency LDAC is also projected to have a higher first cost than the electric alternative, which will further discourage sales.

Industrial applications, although a much smaller market than HVAC applications, do present an excellent opportunity to introduce a high efficiency gas-fired technology. There are important industrial applications where requirements for low humidity air can only be met by gas-fired solid or liquid desiccants. If a 300,000 Btu/h, 1/2-effect regenerator were used to increase the COP of a liquid-desiccant dehumidifier from 0.55 to 1.05 in an industrial process that ran 4,000 hours per year, the annual savings at $\$ 14$ per million Btu for natural gas would be $\$ 15,300$. These savings produce a 1.6 year payback based on the estimated $\$ 24,700$ selling price for the high efficiency regenerator.

The work in this project demonstrated that a $1 \frac{1}{2}$-effect regenerator could achieve a gas-based COP of 1.05. Furthermore the regenerator could operate stably with less than 6 ppm desiccant in the steam output from the regenerator's separator. 


\section{Appendix A}

\section{Final Task Schedule}

\section{Task Schedule}

\begin{tabular}{|c|c|c|c|c|c|c|}
\hline \multirow{2}{*}{$\begin{array}{c}\text { Task } \\
\text { Number }\end{array}$} & \multirow[b]{2}{*}{ Task Description } & \multicolumn{4}{|c|}{ Task Completion Date } & \multirow[b]{2}{*}{ Progress Notes } \\
\hline & & $\begin{array}{l}\text { Original } \\
\text { Planned }\end{array}$ & $\begin{array}{l}\text { Revised } \\
\text { Planned }\end{array}$ & Actual & $\begin{array}{l}\text { Percent } \\
\text { Complete }\end{array}$ & \\
\hline 1 & Heat Flux Limits & $10 / 01 / 03$ & & $11 / 15 / 03$ & $100 \%$ & \\
\hline 2 & Multi-Plate Model & $02 / 01 / 04$ & & $11 / 01 / 04$ & $100 \%$ & \\
\hline 3 & Material Testing & $12 / 01 / 03$ & & 03/01/04 & $100 \%$ & \\
\hline 4 & 1/5 Scale Prototype & $09 / 01 / 04$ & & $5 / 10 / 05$ & $100 \%$ & $\begin{array}{c}\text { Work to be done at } \\
\text { full scale }\end{array}$ \\
\hline 5 & Manufacturing Cost & 03/01/05 & & $9 / 15 / 05$ & $100 \%$ & \\
\hline 6 & HVAC Application & $05 / 01 / 05$ & & 9/15/05 & $100 \%$ & \\
\hline 7 & Lumber Drying Application & 06/01/05 & & $9 / 15 / 05$ & $100 \%$ & $\begin{array}{l}\text { Redirected to Kath- } \\
\text { abar industrial appli- } \\
\text { cations. }\end{array}$ \\
\hline
\end{tabular}




\section{Appendix B}

\section{Final Spending Schedule}

Final Spending Schedule

\begin{tabular}{|c|c|c|}
\hline Task & Approved Budget & Final Project Expenditures \\
\hline Heat Flux Limits & 23,822 & 23,822 \\
\hline Multi-Plate Model & 75,229 & 75,229 \\
\hline Material Testing & 47,521 & 47,521 \\
\hline 1/5 Scale Prototype & 99,278 & 99,278 \\
\hline Manufacturing Cost & 14,903 & 14,903 \\
\hline HVAC Application & 20,973 & 20,973 \\
\hline Lumber Drying Application & 16,774 & 16,774 \\
\hline Total & 298,500 & 298,500 \\
\hline DOE Share & 248,500 & 248,500 \\
\hline Cost Share & 50,000 & 50,000 \\
\hline
\end{tabular}

Project Period: $\quad$ 09/30/03 to 09/30/05 


\section{Appendix C}

\section{Final Cost Share Contribution}

\section{Final Cost Share Contributions}

\begin{tabular}{|r|c|c|c|c|}
\hline \multirow{2}{*}{ Funding Source } & \multicolumn{2}{|l|}{ Approved Cost Share } & \multicolumn{2}{l|}{ Final Contributions } \\
\hline & Cash & In-Kind & Cash & In-Kind \\
\hline AlL Research & 50,000 & & 50,000 & \\
\hline & & & & \\
\hline & & & & \\
\hline & & & & \\
\hline Total & 50,000 & & 50,000 & \\
\hline \multicolumn{6}{|l}{} \\
\hline
\end{tabular}




\title{
Appendix D
}

\author{
Energy Savings Metrics
}

\section{One Unit of Proposed Technology:}

The proposed-technology unit to be used in the energy comparison is a gas-fired $11 / 2$-effect regenerator that would meet the peak water removal demand for a 6,000-cfm liquid-desiccant air conditioner designed to process ventilation air to buildings. Peak water removal capacity is $250 \mathrm{lb} / \mathrm{h}$. The gas-based COP for this regenerator is 1.05 .

\section{One Unit of Current Technology:}

The current-technology unit to be used in the energy comparison is an electric vaporcompression air conditioner that uses a heat-pipe heat exchanger to reach a Sensible Heat Ratio of 0.36. A typical wet-bulb design-day EER for this unit based on compressor power is 11.7. Additional power for condenser fan and higher air-side pressure drops across the heatpipe heat exchanger approximately equal the electrical power for the liquid-desiccant air conditioner with the proposed technology. The current-technology is also sized for $250 \mathrm{lb} / \mathrm{h}$ of water removal.

\section{Discussion of Energy Savings:}

Each unit of the proposed technology and the current technology unit operates at an equivalent of 2000 full-load hours per year. By the year 2010, $1 \%$ of commercial buildings (based on 77.5 billion square feet total floor space shown in 2002 EERE Buildings Energy Databook) use the proposed technology and average ventilation rates are $0.24 \mathrm{cfm}$ per square foot. With these assumptions, there are the equivalent of 31,000 proposed units in operation in 2010.

Each proposed unit uses 504 million Btu natural gas per year. Assuming the same water removal, each current technology uses $70.8 \mathrm{MWh}$ per year. At a heat rate of 10,500 Btu/kWh, primary energy used by the power plant for each current-technology unit is 743 million Btu per year.

The proposed technology produces essentially $100 \%$ latent cooling. The current technology produces approximately one unit of sensible cooling for each two units of latent cooling. During some hours, this sensible cooling will be a benefit and during others, it will be a liability. The net effect of the sensible cooling provided by the current technology is assumed to be negligible.

The energy use of the proposed technology is based on experimentally measured performance. In this project, the prototype of the proposed technology operated with an equivalent COP of 0.95 . However, relatively simple design changes were identified that would increase 
the COP to 1.05 . The projected COP of 1.05 is $16 \%$ lower than the proposed efficiency, but still 1.75 times the efficiency of the current technology for liquid-desiccant regenerators.

\section{Energy Savings Metrics}

\begin{tabular}{|c|c|c|c|c|c|}
\hline & A & B & $C=A-B$ & D & $E=C \times D$ \\
\hline $\begin{array}{c}\text { Type of Energy } \\
\text { Used }\end{array}$ & $\begin{array}{c}\text { Current Tech- } \\
\text { nology } \\
\text { (Btu / yr / unit) }\end{array}$ & $\begin{array}{c}\text { Proposed } \\
\text { Technology } \\
\text { (Btu / yr / unit) }\end{array}$ & $\begin{array}{c}\begin{array}{c}\text { Energy Sav- } \\
\text { ings }\end{array} \\
\text { (Btu / yr / unit) }\end{array}$ & $\begin{array}{l}\text { Estimated } \\
\text { Number of } \\
\text { Units in U.S. } \\
\text { by } 2010 \\
\text { (units) }\end{array}$ & $\begin{array}{c}\begin{array}{c}\text { Energy Savings } \\
\text { by } 2010 \\
\text { (Btu / yr) }\end{array} \\
\end{array}$ \\
\hline \multicolumn{6}{|l|}{ Oil / Gasoline } \\
\hline Natural Gas & & 504 million & 239 million & 31,000 & 7,400 billion \\
\hline \multicolumn{6}{|l|}{ Coal } \\
\hline $\begin{array}{c}\text { Electricity (@ } \\
\text { 10,500 Btu / kWh) }\end{array}$ & 743 million & & & & \\
\hline \multicolumn{6}{|l|}{$\begin{array}{l}\text { Other Energy } 1 \\
\text { (Explain) }\end{array}$} \\
\hline \multicolumn{6}{|l|}{$\begin{array}{l}\text { Other Energy } 2 \\
\text { (Explain) }\end{array}$} \\
\hline \multicolumn{6}{|l|}{$\begin{array}{c}\text { Other Energy ...n } \\
\text { (Explain) }\end{array}$} \\
\hline Total Per Unit & 743 million & 504 million & 239 million & & \\
\hline
\end{tabular}

